\title{
Investigation of the Influence of Bonding and Thermal Ageing Duration on the Peeling Strength of Knitted Materials' Bonds
}

\author{
Gerda MIKALAUSKAITÉ *, Virginija DAUKANTIENE்
}

Department of Production Engineering, Kaunas University of Technology, Studentu str. 56, LT-51424 Kaunas, Lithuania

crossref http://dx.doi.org/10.5755/j01.ms.26.2.21666

Received 17 September 2018; accepted 27 January 2019

\begin{abstract}
Bonding technology namely as "sew free" technology is usually applied for joining the pieces of sportswear and leisure clothing. Influence of the thermal ageing duration on the peeling strength of woven fabric and knitted materials bonded at $150^{\circ} \mathrm{C}$ temperature for $10 \mathrm{~s}, 20 \mathrm{~s}, 30 \mathrm{~s}$, and $40 \mathrm{~s}$ durations with two polyurethane films of $0.175 \mathrm{~mm}$ and $0.127 \mathrm{~mm}$ thicknesses has been investigated in this research. Based on the research results it was shown that the peeling strength of the textile bonds is dependent on material type and bonding duration, but it is not highly affected by the ageing at $45^{\circ} \mathrm{C}$ temperature for $150 \mathrm{~min}, 300 \mathrm{~min}$, and $450 \mathrm{~min}$. During concluding it may be stated that ageing at $45^{\circ} \mathrm{C}$ temperatures is not main factor influencing the bond quality during its exploitation in high temperature environment.

Keywords: knitted material, bonding, strength, thermal ageing, polyurethane adhesive film, SEM.
\end{abstract}

\section{INTRODUCTION}

In recent years, bonding technology namely as "sew free" technology is being increasingly applied in sportswear and leisure wear engineering applications [1-4]. The pieces of clothing could be bonded together by using thermoplastic polyurethane adhesive films which are applied between two materials surfaces with the application of high temperature and pressure for certain time duration [1, 5]. It allows the elimination of sewing for many applications, including seams, hems, etc. as well as brings both economic and aesthetic benefits [6]. The advantages of bonds may be their lower thickness and friction $[7,8]$, and higher plasticity compared with sewn seams [9]. Bonds have the potential advantage of design flexibility and ease of fabrication [10]. Bonded garment typically weighs less than a sewn garment due to reason that only one clothing piece seam allowance instead of two ones used for seam stitching by thread is designed for the bond formation. Bonds are less permeable to air compared to the sewn seams [11]. Adhesive technology may be also applied to perform sealing functions ensuring the waterproofness of seams $[12,13]$.

Adhesive bonding is a physical-chemical process. Thermally activated thermoplastic adhesive softens, melts and fills the irregularities of textile surfaces or pores inside structure [12, 13]. The strong bond, which usually is even stronger than sewn seam, is formed after cooling [2,9]. Bond quality depends on the materials anisotropy, tensile characteristics of thermoplastic films [3], bonding parameters, textile bearing surface and structure mobility $[2,3,14]$ as well as on bond peeling velocity [15].

Increased interest of the bond application influences higher demand for information concerning their properties like bond strength. One of the most important parameters influencing bond strength is bonding temperature $[16,17]$.

\footnotetext{
* Corresponding author. Tel.: +370-37-300 237.

E-mail address: gerda.mikalauskaite@ktu.edu (G. Mikalauskaitė)
}

From the other side, the consideration of temperature impact in respect to ageing problem during wear, e. g. in the tropic climate, also is important. The suppliers' recommendations will rarely indicate the influence of temperature on the strength of adhesive, the temperature range over which it can be used and the expected deterioration in the physical properties (rate of ageing) when used in particular environments [10]. The performance of adhesive bonds in footwear as well as in clothing may deteriorate in storage or in wear. Many textile fibres like polyester having a wide range of applications [18] are thermoplastic, and thus heat sensitive. Polyester fibres may shrink in length or even melt on exposure to thermal conditions. Modern fabrics such as those based on microfibers with sophisticated surface finishes, e.g. "peach skin" effects, are especially sensitive to both temperature and pressure [12]. Thus, the impact of high temperature may be simulated and considered as the thermal ageing factor of both textiles and their bonds. The standard LST EN 15062 [19] describes laboratory test methods applying specified ageing conditions to simulate and to assess the deterioration of adhesive bonds which may occur as part of usual footwear worn and stored in normal practice by natural ageing. The ageing problems are also analysed in aircraft [10]. Thermoplastic elastomers (TPU) are extensively applied as an anti-vibration material in machinery, and etc. Therefore, their bonding and thermal aging properties are also important for the forecasting of their mechanical properties [20]. The aging temperature combined to the water also seems to be governing factor of the TPU degradation [21]. The importance of the aforesaid problem proves the demand for reliable research information concerning the thermal ageing of bonds as well as the procedure of its simulating and testing in clothing industry.

Thus, the aim of this research was both the simulation of textile bond thermal ageing and the evaluation of its influence on bond peeling strength. 


\section{EXPERIMENTAL}

\subsection{Materials}

Investigations were performed with commercially available woven fabric $\mathrm{W} 1$ and knitted fabrics $\mathrm{K} 1, \mathrm{Ks} 1$, $\mathrm{Ks} 2, \mathrm{Ks} 3, \mathrm{Ks} 4$, and Ks5 suitable for sportswear or leisure wear production. The characteristics of the investigated textiles are presented in Table 1. Textile thickness was measured according to the standard EN ISO 5084 [22]. Textile area density was determined according to the standard LST EN 12127 [23]. Determination of number of threads per unit length of woven fabric was carried out according to the standard LST EN 1049 [24], and the number of stitches per unit length of knitted materials was determined according to the standard EN ISO 14971 [25].

Textiles were bonded with commercially available thermoplastic polymeric resin polyurethane (PU) dry films $\mathrm{T} 1$ and $\mathrm{T} 2$ of $8 \mathrm{~mm}$ width suitable for fabric-to-fabric substrates (Table 1).

\subsection{Bond peeling strength testing methodology}

Thermoplastic adhesive films are reactivated by heat to ensure excellent coating uniformity. For the purpose to ensure reliable bond between textile substrates, the bonding parameters should be controlled: pressure, temperature, and duration. Thus, bonding conditions were adjusted by taking into account the recommendations of thermoplastic film producer as well as the previous investigations [16, 17, 26, 27]. The film T1 was applied for the bonding of the textile specimens' Ks1, Ks2, Ks3, Ks4, and Ks5, and the film $\mathrm{T} 2$ - for bonding of $\mathrm{W} 1, \mathrm{~K} 1$, and Ks1 textiles. W1 and K1 textiles were chosen for the comparison of bond peeling strength between woven and knitted fabrics. Ks1 textile bonds were tested for both T1 and $\mathrm{T} 2$ adhesive film cases intending to illustrate the influence of the film type on bond peeling strength. The investigation of the textile bonds $\mathrm{Ks} 1$ _T1, Ks2_T1, Ks3_T1, Ks4_T1, and Ks5_T1 characterised the behaviour of polyester knitted fabrics' bonds containing different amount of the elastane fibre which varied from $4 \%$ up to $20 \%$ (Table 1).

The pairs of $20 \mathrm{~mm} \times 80 \mathrm{~mm}$ lengthwise textile samples were bonded with $8 \mathrm{~mm} \times 50 \mathrm{~mm}$ adhesive tapes by applying the pressing device GTK DEA $25 \mathrm{R}$ at $5.6 \mathrm{kPa}$ pressure at $150{ }^{\circ} \mathrm{C}$ temperature for the different bonding duration $t(10 \mathrm{~s} ; 20 \mathrm{~s} ; 30 \mathrm{~s}$; and $40 \mathrm{~s})$.

The lengthwise textile specimens were chosen by taking into account the construction instructions commonly being applied in the clothing industry which consider that clothing pieces should be placed warp/wale direction during their cutting from textile materials. Even if one of the previous publications [3] states, that the orientation of knitted materials pieces in bonded seams does not have any significant effect, whereas the other research study [17] reveals that the fabric orientation in the bond makes significant influence on the peeling strength of the lengthwise specimens bonded at both $150{ }^{\circ} \mathrm{C}$ and $160{ }^{\circ} \mathrm{C}$ temperatures. Additionally, based on the published research works it may be concluded that, the selected bonding temperature $\left(150{ }^{\circ} \mathrm{C}\right)$ does not exceed the glass transition temperature $\left(T_{g}=226^{\circ} \mathrm{C}\right)$ of polyester fibres refereed in the researches had been published by other scientist (https://us.setaram.com), previously. There were shown, that the characteristics of a pristine adhesive bond kept well below its glass transition temperature should remain stable for extended periods of time [10]. Therefore, it may be assumed that the chosen bonding temperature is optimal for the current investigation.

Samples were conditioned in standard atmosphere conditions ( $65 \pm 4 \% \mathrm{RH}$ and $20 \pm 2{ }^{\circ} \mathrm{C}$ temperature) for 24 hours before bond peeling strength testing according to the standard LST EN ISO 139 [28]. Then the samples were exposed to $45 \pm 5^{\circ} \mathrm{C}$ temperature in the oven chamber E5CN for the thermal ageing durations: $t_{h}=150 \mathrm{~min}$, $300 \mathrm{~min}$, and $450 \mathrm{~min}$. Expose of the textile bonds to the high temperature for certain duration may be considered as their ageing being standardized in the standard LST EN 15062 [19] suitable for the adhesives for leather and footwear materials. Whereas, this type of standard for textile adhesive bonds is missing; thus, the bond ageing temperature was selected as average value $\left(45 \pm 5{ }^{\circ} \mathrm{C}\right)$ between two temperatures which falls within the limits of ageing temperature for leather and footwear materials adhesives as well as the average temperature of both ageing in warm air cabinet with forced ventilation capable at $\left(50 \pm 2^{\circ} \mathrm{C}\right)$ temperature and moist ageing in glass container at $\left(40 \pm 2{ }^{\circ} \mathrm{C}\right)$ temperature according to the standard LST EN 15062 [19]. Temperature of the tropic climate zones also was assumed [29].

Table 1. The characteristics of investigated textile materials and thermoplastic adhesive films

\begin{tabular}{|c|c|c|c|c|c|c|}
\hline \multirow{2}{*}{ Code } & \multirow{2}{*}{ Content } & \multirow{2}{*}{ Structure } & \multicolumn{2}{|c|}{ Density along direction, $\mathrm{cm}^{-1}$} & \multirow{2}{*}{ Thickness, mm } & \multirow{2}{*}{ Area density, $\mathrm{g} / \mathrm{m}^{2}$} \\
\hline & & & Warp/Wale & Weft/Course & & \\
\hline \multicolumn{7}{|c|}{ Textile materials } \\
\hline $\mathrm{W} 1$ & $100 \%$ Polyester & Plain woven & $42.0 \pm 2.3$ & $57.0 \pm 4.1$ & $0.28 \pm 0.01$ & $150.6 \pm 2.1$ \\
\hline K1 & $100 \%$ Polyester & Interlock & $18.0 \pm 1.0$ & $16.0 \pm 0.6$ & $0.56 \pm 0.02$ & $113.2 \pm 4.9$ \\
\hline Ks1 & $96 \%$ Polyester, $4 \%$ Elastane & Interlock & $22.0 \pm 0.5$ & $18.0 \pm 0.5$ & $0.90 \pm 0.02$ & $251.6 \pm 2.0$ \\
\hline Ks2 & $84 \%$ Polyester, $16 \%$ Elastane & Plain jersey & $33.0 \pm 0.5$ & $21.0 \pm 0.5$ & $0.69 \pm 0.02$ & $218.8 \pm 2.0$ \\
\hline Ks3 & $90 \%$ Polyester, $10 \%$ Elastane & Plain jersey & $28.0 \pm 0.5$ & $14.0 \pm 0.5$ & $0.59 \pm 0.01$ & $235.5 \pm 1.8$ \\
\hline Ks4 & $87 \%$ Polyester, $13 \%$ Elastane & Warp knitted & $27.0 \pm 0.5$ & $22.0 \pm 0.5$ & $0.63 \pm 0.01$ & $254.0 \pm 4.0$ \\
\hline Ks5 & $80 \%$ Polyester, $20 \%$ Elastane & Warp knitted & $47.0 \pm 0.5$ & $30.0 \pm 0.5$ & $0.47 \pm 0.01$ & $218.0 \pm 2.1$ \\
\hline \multicolumn{7}{|c|}{ Thermoplastic adhesive films } \\
\hline Code & Content & \multicolumn{3}{|c|}{ Thickness, mm } & \multicolumn{2}{|c|}{ Melting point, ${ }^{\circ} \mathrm{C}$} \\
\hline $\mathrm{T} 1$ & Polyurethane (PU) & \multicolumn{3}{|c|}{0.175} & \multicolumn{2}{|c|}{$90-100$} \\
\hline $\mathrm{T} 2$ & Polyurethane (PU) & \multicolumn{3}{|c|}{0.127} & \multicolumn{2}{|c|}{95} \\
\hline
\end{tabular}


For a thin, $10-200 \mu \mathrm{m}$ adhesive layer, tensile forces will be dominant [10], thus the destructive examination was performed with computerized CRE-type tension machine H10KT (TINIUS OLSEN) to evaluate the influence of both bonding and ageing durations on the bond peeling strength. Peeling speed was kept at $50 \mathrm{~mm} / \mathrm{min}$. The strength $F(\mathrm{~N} / \mathrm{mm})$ was calculated from the typical peeling curves. The number of samples in each group varied from 5 up to 6 . The variation coefficient was determined being within the limits of $2.3 \%$ and $14.0 \%$.

The changes in textile bond morphology before and after thermal ageing was controlled by applying SEM method realized with QUANTA200FEG. This method was suggested also by previous researches as being suitable to explain the obtained strength values of the bonds [2].

\section{RESULTS AND DISCUSSION}

The dependencies between the bond peeling strength $F$ and bonding duration $t$ of the investigated textile bonds are presented in Fig. 1. These curves may be significantly approximated by the polynomial equation, in exception the samples Ks2_T1 $\left(R^{2}=0.4500\right)$ and Ks4_T1 $\left(R^{2}=0.7834\right)$ (Fig. 1). The determination coefficient $R^{2}$ varied from 0.4500 for bond Ks2_T1 up to 0.9886 for bond Ks3_T1.

Aforesaid results show, that the values of bond peeling strength $F$ (Fig. 1) have decreased by $25.2 \%$ and by
$34.6 \%$ for two interlock knitted fabrics' $\mathrm{K} 1$ and $\mathrm{Ks} 1$ samples, respectively, using the thinner film T2, supposedly, due to too long duration for the penetration of melted adhesive into knitted structure (Fig. 1). T2 film application for W1 woven fabric bonding influenced the significant increase in bond peeling strength $(81.7 \%)$ while increasing the bonding duration from $10 \mathrm{~s}$ up to $40 \mathrm{~s}$. This evidences, that longer duration is needed for the penetration of adhesive into tighter structure of W1 woven fabric than of knitted fabrics. Bond peeling strength of the bonds of polyester knitted fabrics containing different elastane amount which varies from $4 \%$ up to $20 \%$ (Table 1) and thicker adhesive film T1 has increased from $19.8 \%$ (Ks5_T1) up to $320.8 \%$ (Ks3_T1), dependently on textile structure, after increase in bonding duration up to $40 \mathrm{~s}$. It is worth mention, that very high increase in bond peeling strength $(101.2 \%)$ was also determined for Ks2_T1 knitted fabric. Both Ks2 and Ks3 knitted fabrics were of the plain knitted structure.

The maximal bond peeling strength $(6.12 \mathrm{~N} / \mathrm{mm})$ has been determined for the polyester knitted fabric without elastane fibre K1_T2 for $10 \mathrm{~s}$ bonding duration. Both density and thickness of $\mathrm{K} 1$ fabric was one of the minimal (Table 1) between investigated textiles. Thus, it may be assumed, that it absorbs melted adhesive more regularly and deeper than other textiles being under testing.

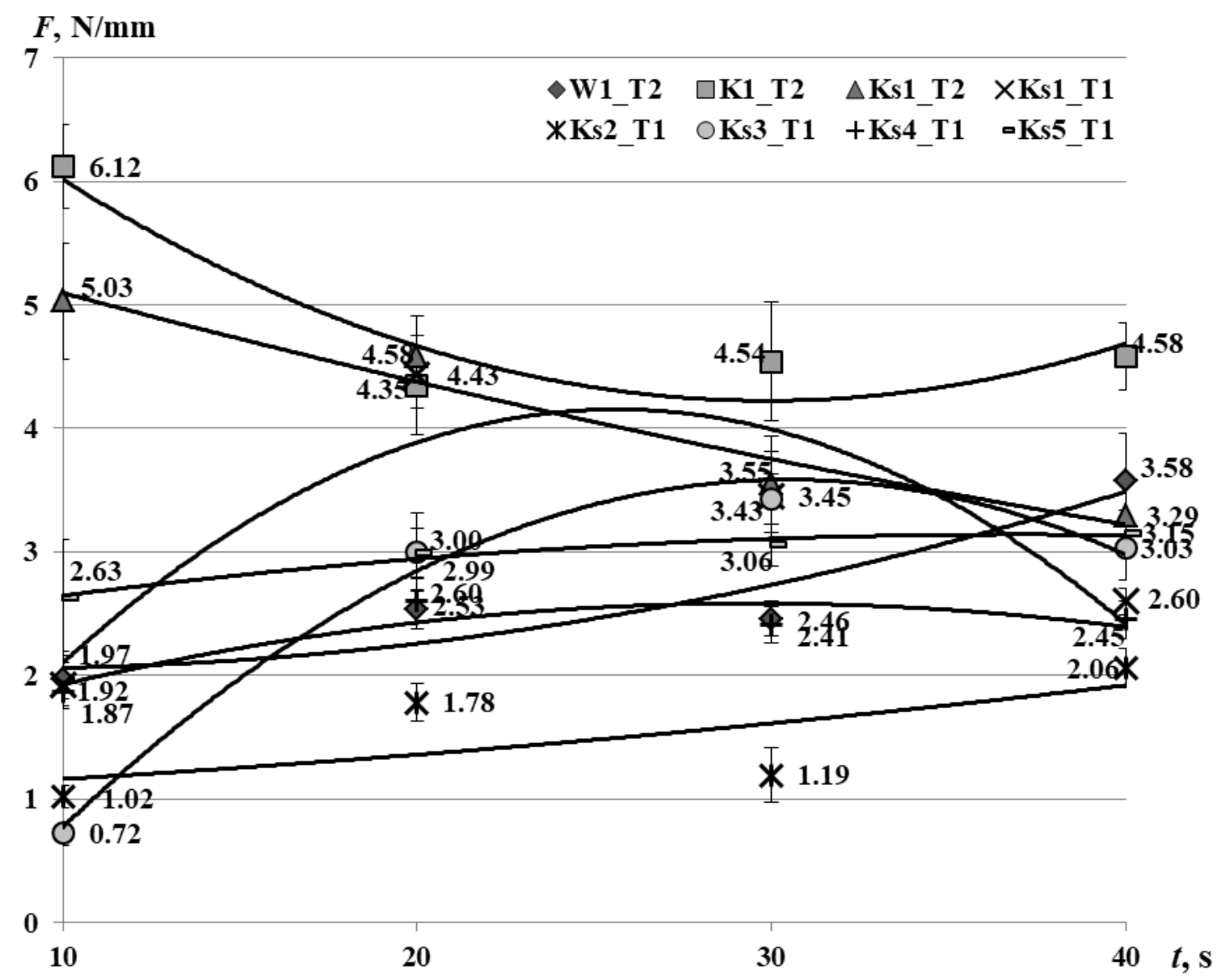

Fig. 1. Dependencies between bond strength $F$ and bonding duration $t$ for the ageing duration $t_{h}$ of 0 min 


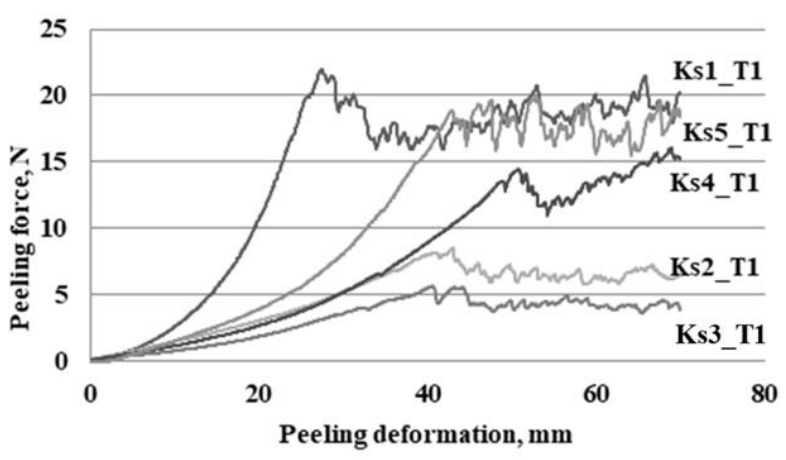

a

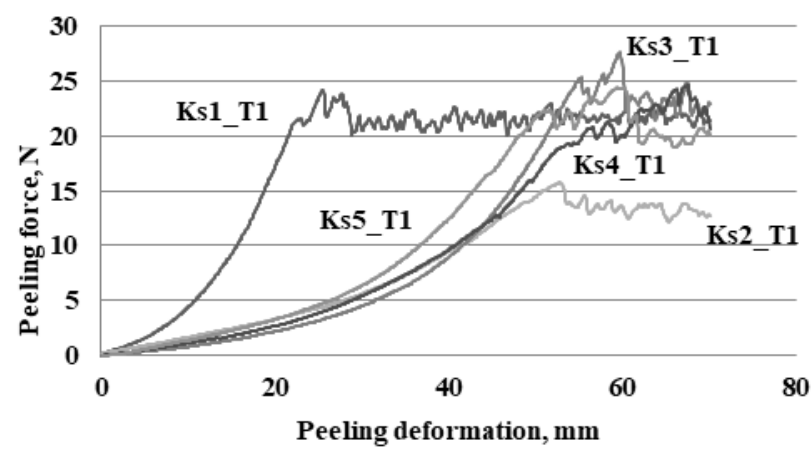

$\mathrm{c}$

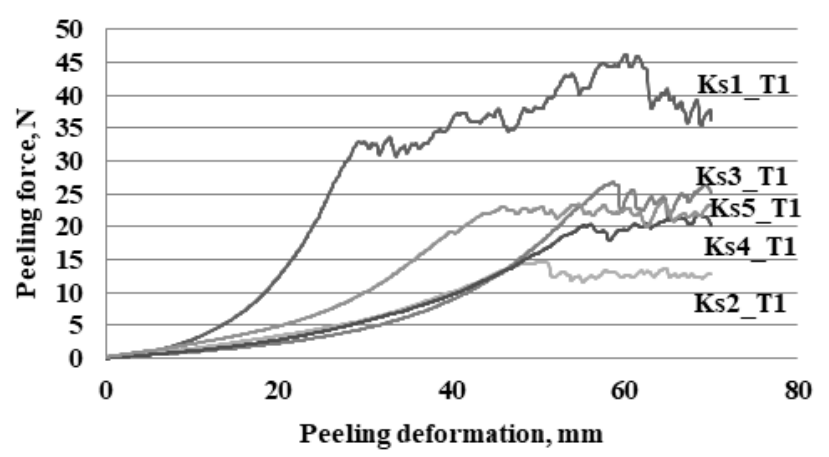

$\mathrm{b}$

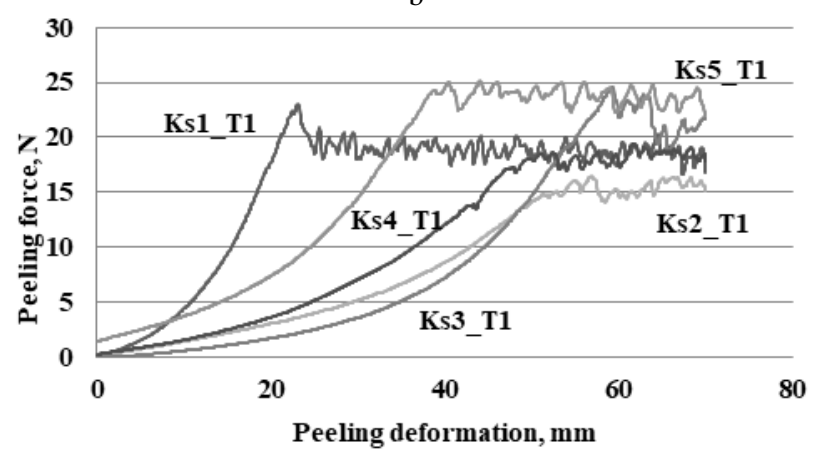

$\mathrm{d}$

Fig. 2. The peeling curves of the investigated textile bonds for bonding duration: $a-10 s ; b-20 s ; c-30 s ; d-40 s$

And, the thinner $(0.127 \mathrm{~mm})$ polyurethane adhesive film (T2) is optimal for the formation of the strong cohesive bond between two layers of textile fabric K1. High bond peeling strength was determined for both $\mathrm{K} 1 \_\mathrm{T} 2$ and Ks1_T2 $(5.03 \mathrm{~N} / \mathrm{mm})$ bonds laminated with the film T2 of lower thickness $(0.127 \mathrm{~mm})$ for $10 \mathrm{~s}$ bonding duration. Thus, while making comparison analysis between two investigated cases Ks1_T2 and Ks1_T1 of the same polyester interlock knitted fabric which contains $4 \%$ of elastane fibre, but uses the adhesive polyurethane films T2 and $\mathrm{T} 1$ of the different thicknesses $-(0.127 \mathrm{~mm})$ and $(0.175 \mathrm{~mm})$, respectively, it may be concluded, that higher amount of melted adhesive is not necessary for the formation of the sufficiently strong adhesive bond for $10 \mathrm{~s}$ duration (Fig. 1). Adhesive film thickness influences the different impact of bonding duration on bond peeling strength. The peeling strength of Ks1_T2 bond decreased in $34.6 \%$ after increase in bonding duration from $10 \mathrm{~s}$ up to $40 \mathrm{~s}$ due to too deep absorption of $\mathrm{T} 2$ film melted adhesive into textile structure.

The bond Ks1_T1 is much weaker than one of Ks1_T2 bond for $10 \mathrm{~s}$ bonding. When using the thicker $(0.175 \mathrm{~mm})$ film $\mathrm{T} 1$ peeling strength increases increasing bonding duration from $20 \mathrm{~s}$ up to $40 \mathrm{~s}$, and resembling it to the values of the peeling strength have been determined for this fabric's bonds being laminated with T2 thinner $(0.127 \mathrm{~mm})$ film. Ks1 fabric is the thickest and the long bonding duration had been applied to it has influenced the deep penetration of adhesive into textile structure influencing, supposedly, stronger mechanical adhesion within the knitted fabrics' structure, but weaker cohesion within adhesive interlayer $[6,30]$ when using thinner adhesive film.
The minimal increase $(19.8 \%)$ in the peeling strength due to increasing the bonding duration up to $40 \mathrm{~s}$ was determined for Ks5_T1 sample while comparing it with other ones of the polyester knitted fabrics containing elastane fibre being under investigation. The fabric Ks5 is the thinnest and of the highest density as well as it contains highest amount of elastane fibre $(20 \%)$. While analysing the influence of bonding duration had been changed from $10 \mathrm{~s}$ up to $40 \mathrm{~s}$ on the peeling strength for the bonds laminated from two substrates of polyester knitted fabrics containing elastane (Fig. 1) being under investigations applying the thin film T1, it worth to mention that the bond peeling strength increases significantly, i. e. from $19.8 \%$ for Ks5_T1 up to $320.8 \%$ for Ks3_T1. And, the first step of the bonding duration increase by $10 \mathrm{~s}$ makes the significant influence on the peeling strength which has increased from $39.0 \% \mathrm{Ks} 4$ _T1 up to $316.7 \% \mathrm{Ks} 3 \_\mathrm{T} 1$. Later, during increasing the bonding duration up to $30 \mathrm{~s}$ the changes in the values of peeling strength varies within the measurement errors limits with the increasing tendency, but afterwards had been applied increasing of the bonding duration up to $40 \mathrm{~s}$ has influenced the decrease in the values of peeling strength for the aforesaid bonds. Thus, it may be concluded that the bonding duration which approximately equals to both $20 \mathrm{~s}$ and $30 \mathrm{~s}$ may be considered as being optimal for the adhesive bonding of the polyester knitted fabrics containing elastane fibre being under investigations. The tendency of the knitted fabric bonds' peeling strength's increase due to increase in bonding duration may be explained by loose knitted structure which effectively absorbs the melted adhesive into the pores between yarns and fibres influencing the 
formation of thin adhesive layer between two layers of textile fabric (Fig. 4).

Analysis of the typical peeling curves of the knitted fabrics with different per cent elastane fibre being under investigations (Fig. 2) has shown that the lowest amplitude of peeling force oscillation is determined for $40 \mathrm{~s}$ bonding duration (Fig. 2 d), supposedly, due to even distribution of the melted adhesive polymer in the space between two textile substrates being under investigations. The bonding duration of $40 \mathrm{~s}$ also seems being optimal for the thickest interlock knitted fabric Ks1 which demonstrates the high oscillation in peeling force for both $10 \mathrm{~s}$ and $20 \mathrm{~s}$ bonding

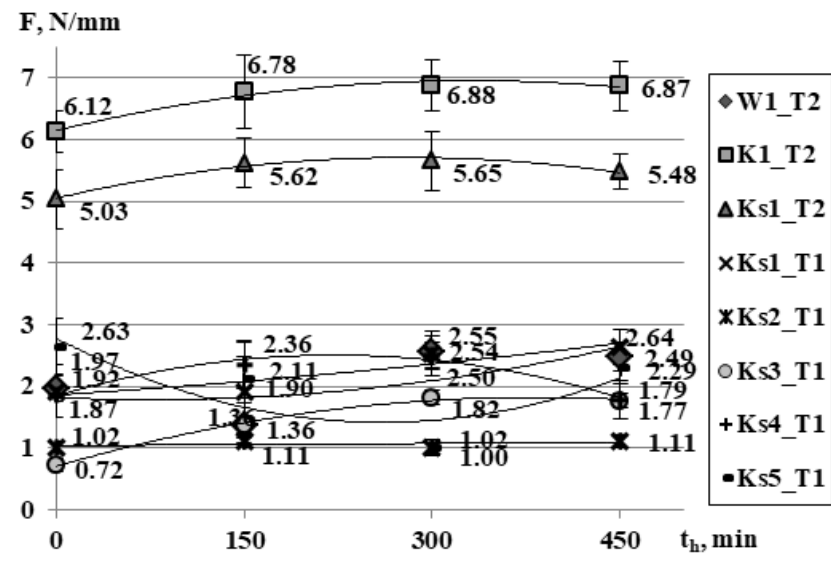

a

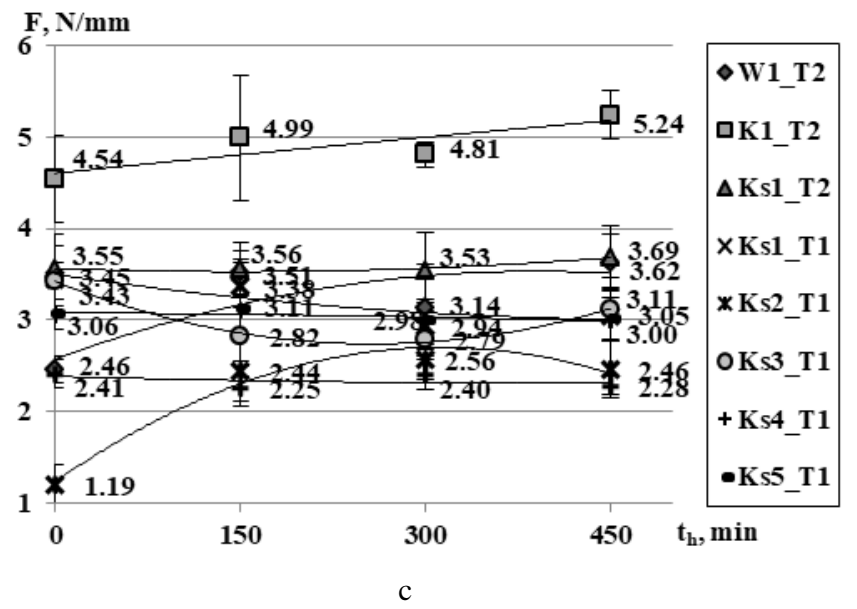

durations (Fig. $2 \mathrm{a}$ and b) as well as introduces not very high increase in the bond peeling strength $(35.4 \%)$ due to bonding duration increase comparing with the knitted fabrics containing elastane being under investigations.

The relationships between bond peeling strength $F$ and ageing duration $t_{h}$ for the investigated textile bonds are presented in Fig. 3. Summary of the empirical coefficients $\left(a, b\right.$ and $c$ ) and determination coefficients $\left(R^{2}\right)$ of the polynomial equation $(y=a x 2+b x+c)$ which is presented in Table 2 prove the significance of aforesaid relationship, in exception the cases being marked in the grey-coloured squares.

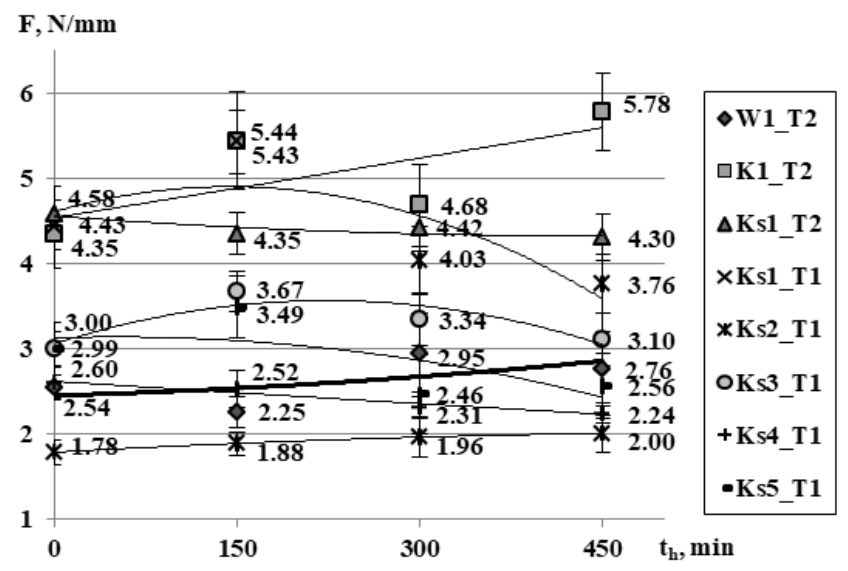

b

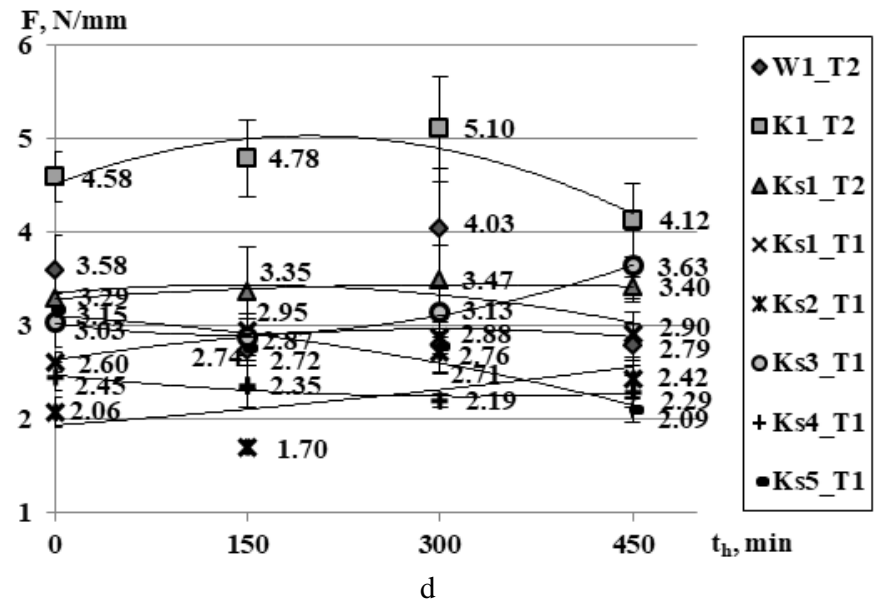

Fig. 3. The dependencies between peeling strength $F$ and thermal ageing duration $t_{h}$ for: $\mathrm{a}-10 \mathrm{~s}$ bonding duration; $\mathrm{b}-20 \mathrm{~s}$ bonding duration; $\mathrm{c}-30 \mathrm{~s}$ bonding duration; $\mathrm{d}-40 \mathrm{~s}$ bonding duration

Table 2. Summary of empirical coefficients $(a, b$ and $c)$ and determination coefficient $\left(R^{2}\right)$ of the polynomial equation $\left(y=a x^{2}+b x+c\right)$

\begin{tabular}{|c|c|c|c|c|c|c|c|c|}
\hline \multirow{2}{*}{ Coefficients } & \multicolumn{8}{|c|}{ Bond type } \\
\hline & W1_T2 & K1_T2 & Ks1_T2 & Ks1_T1 & Ks2_T1 & Ks3_T1 & Ks4_T1 & Ks5_T1 \\
\hline \multicolumn{9}{|c|}{$10 \mathrm{~s}$ bonding duration } \\
\hline$R^{2}$ & 0.4938 & 0.9746 & 0.9737 & 0.846 & 0.2000 & 0.9930 & 0.9665 & 0.7006 \\
\hline \multicolumn{9}{|c|}{$20 \mathrm{~s}$ bonding duration } \\
\hline$R^{2}$ & 0.3496 & 0.4752 & 0.7313 & 0.6125 & 0.9993 & 0.7771 & 0.9580 & 0.4663 \\
\hline \multicolumn{9}{|c|}{$30 \mathrm{~s}$ bonding duration } \\
\hline$R^{2}$ & 0.6867 & 0.7058 & 0.8334 & 0.7711 & 0.9674 & 0.9901 & 0.1632 & 0.4802 \\
\hline \multicolumn{9}{|c|}{$40 \mathrm{~s}$ bonding duration } \\
\hline$R^{2}$ & 0.0765 & 0.8004 & 0.8212 & 0.8258 & 0.3813 & 0.9950 & 0.8562 & 0.8917 \\
\hline
\end{tabular}


Increase in the bond peeling strength for majority of the bonds being under investigations was determined after application of the first stage of thermal ageing (150 min) for all bonding durations being under evaluation (Fig. 3). On the other hand, these changes for the majority of the bond cases being under investigation vary within the measurement errors' limits when changing the bonding duration from $150 \mathrm{~min}$ up to $450 \mathrm{~min}$. It may be noticed an exceptional case, that the impact of thermal ageing on the peeling strength of the polyester K1 knitted fabric's bond laminated applying the thicker adhesive film T2 is most significant comparing with the one of the other textiles' bonds being under investigations. Through, the case of the longest bonding duration (40 s) for the aforesaid bond K1_T2 (Fig. 3 d) negotiates the importance of the thermal ageing on peeling strength.

Also, it is interesting to notice that the bonds being bonded from two substrates of the polyester knitted fabric K1 with the thicker adhesive film T2 was strongest among all adhesive bonds being under investigation independently on both bonding and thermal ageing durations. For aforesaid case, the maximal peeling strength $(6.88 \mathrm{~N} / \mathrm{mm})$ was determined for $10 \mathrm{~s}$ bonding duration, independently on ageing duration, and the minimal one $(4.12 \mathrm{~N} / \mathrm{mm})-$ for both $40 \mathrm{~s}$ bonding and $450 \mathrm{~min}$ thermal ageing in the oven chamber durations.

SEM images for Ks1_T1 control (Fig. 4 a) and thermally aged (Fig. 4 b) samples were analysed to introduce the influence of both bonding $t$ and thermal ageing $t_{h}$ duration on textile bond morphology. Ks1_T1 bond was chosen due to the notification while analysing the results presented in Fig. 1, that the peeling strength of the aforesaid bond was approximately equal to an average value within the range of ones have been determined for other bonds being under investigations (Fig. 1).

And, the maximal duration of the thermal ageing $\left(t_{h}=450 \mathrm{~min}\right)$ influences small changes in the morphology's images of the analysed textile bonds as there are some evidences for immigration of PU adhesive between fibers of upper and lower surfaces at higher ageing times (450 min) (Fig. 4 b)

\section{CONCLUSIONS}

1. In the current contribution, bond peeling strength testing has been used to study the influence of both bonding and thermal ageing duration on bond quality. The following findings were derived from this experimental study:

- the peeling strength of textile bonds was dependent on structure of the textiles being under investigations; the peeling strength of the polyester knitted fabric K1 samples bonded with the thinner adhesive film T2 was highest compared with other polyester textiles being under investigations;

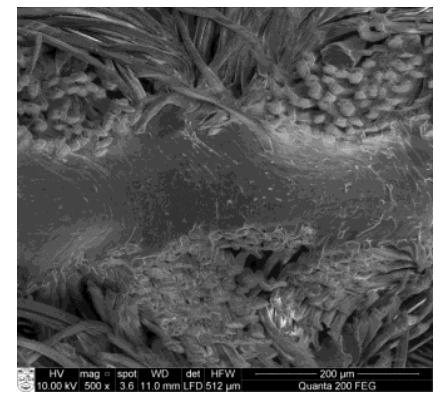

Ks1_T1

$t=10 \mathrm{~s} ; t_{h}=0 \mathrm{~min}$

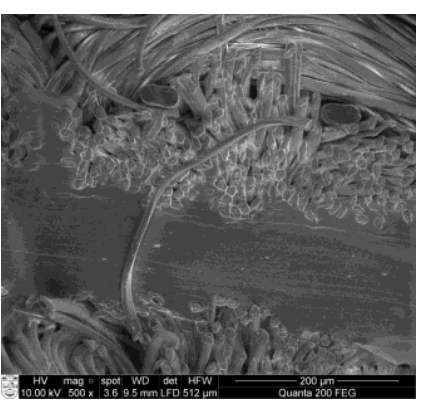

$\mathrm{Ks} 1 \_\mathrm{T} 1$

$t=10 \mathrm{~s} ; t_{h}=450 \mathrm{~min}$

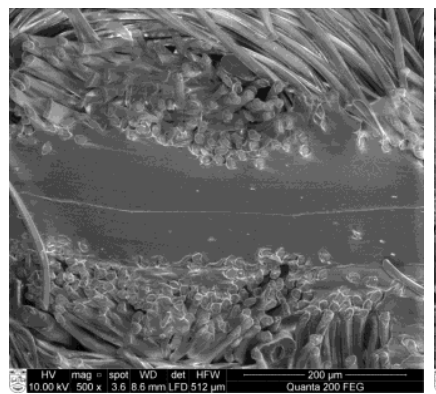

Ks1_T1

$t=20 \mathrm{~s} ; t_{h}=0 \mathrm{~min}$

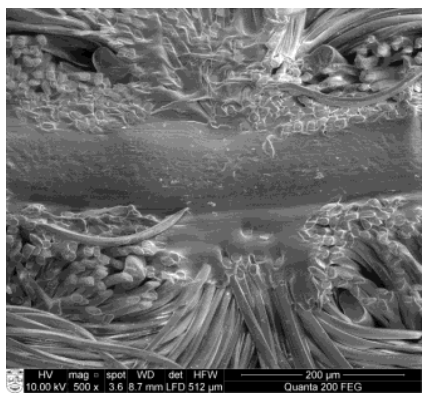

Ks1_T1

$t=30 \mathrm{~s} ; t_{h}=0 \mathrm{~min}$

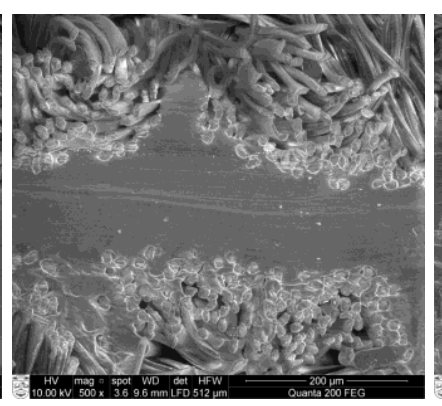

Ks1_T1

$t=20 \mathrm{~s} ; t_{h}=450 \mathrm{~min}$

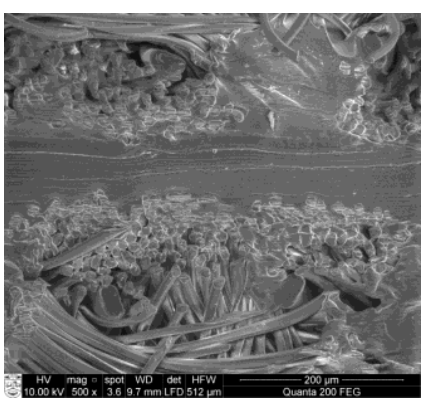

Ks1_T1

$t=30 \mathrm{~s} ; t_{h}=450 \mathrm{~min}$

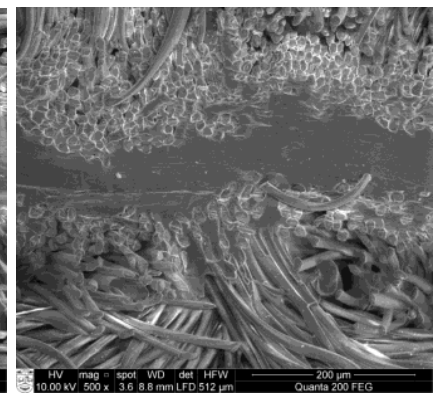

Ks1_T1

$t=40 \mathrm{~s} ; t_{h}=0 \mathrm{~min}$

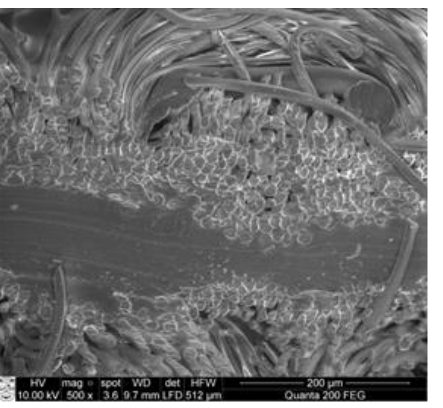

Ks1_T1

$t=40 \mathrm{~s} ; t_{h}=450 \mathrm{~min}$

b

Fig. 4. SEM images of the textile bonds (Ks1_T1) laminated for $10 \mathrm{~s} ; 20 \mathrm{~s} ; 30 \mathrm{~s}$; and 40 durations $t$ for control: a-not exposed by thermal ageing; $\mathrm{b}$ - exposed by 450 min ageing duration $t_{h}$ samples 
- the increase in bonding duration $t$ from $10 \mathrm{~s}$ up to $40 \mathrm{~s}$ influences the increase in peeling strength $F$ for the knitted fabrics containing elastane fibre, but it tends to be decreased for knitted fabric without elastane, if compared with the case of $10 \mathrm{~s}$ bonding temperature;

- the comparison of the textiles' bonds for the woven and knitted materials without elastane fibres had shown that the increase in the bonding temperature increased the bond peeling strength of the woven fabric W1 and decreased for knitted fabric K1 if compared with the case of $10 \mathrm{~s}$ bonding temperature;

- the influence of the ageing at $45^{\circ} \mathrm{C}$ temperature on the peeling strength was very small for the different ageing durations applying all bonding durations.

2. Thus concluding finally, it should be stated that the ageing duration at $45^{\circ} \mathrm{C}$ temperature is not that factor which makes significant influence on the textile bonds quality during their exploitation, for example, in the tropic climate zones. Longer thermal ageing duration also is not relevant for the simulation of clothing exploitation as the wearer would not be able to endure the temperatures higher than $45^{\circ} \mathrm{C}$ for $450 \mathrm{~min}$ and longer. Thus, for the future investigations the major focus should be concentrated on the estimation of bonding temperature influence on the mechanical properties of textile materials applying the methods of both differential scanning calorimetry (DSC) and dynamic mechanical thermal analysis (DMTA). Choosing the bonding temperature which influences the increase in bond peeling strength $[10,17]$ the destruction of the thermoplastic fibres that compiles knitted fabric, should be avoided, which may weaken the material itself.

\section{REFERENCES}

1. Seram, N., Nandasiri, T.A. A Comparison between Bonding and Sewing: Application in Sports Performance Wear Journal of Academia and Industrial Research 8 2015: pp. 343-345.

2. Jakubčionienė, Ž., Masteikaitè, V. Investigation of Textile Bonded Seams Materials Science (Medžiagotyra) 16 (1) 2010: pp. $76-79$.

http://dx.doi.org/10.5755/j01.ms.18.2.1922

3. Busilienė, G., Strazdienė, E., Urbelis, V., Krauledas, S. The Effect of Bonded Seams upon Spatial Behaviour of Knitted Materials Systems Materials Science (Medžiagotyra) 21 (2) 2015: pp. 271-275. https://doi.org/10.5755/j01.ms.21.2.5767

4. Shishoo, R. (Ed.). The Global Textile and Clothing Industry: Technological Advances and Future Challenges. Woodhead Publishing Limited, Cambridge, 2012: pp. 55-76.

5. Jana, P. Assembling Technologies for Functional Garments. An Overview Indian Journal of Fibre and Textile Research 36 2011: pp. 380-387.

6. Pizzi, A., Mittal, K.L. Handbook of Adhesive Technology. CRC press, London, 2017: pp. 73 - 76.

7. Busilienė, G., Strazdienė, E., Urbelis, V., Krauledas, S. The Investigation of Knitted Materials Bonded Seams Behaviour Upon Cyclical Fatigue Loading Materials Science (Medžiagotyra) 23 (2) 2017: pp. 180-185. http://dx.doi.org/10.5755/j01.ms.23.2.16065

8. Yick, K.L., Hui, C.Y. Sew-free Technologies for Intimate Apparel In Advances in Women's Intimate Apparel Technology 2016: pp. 89-106.

9. Boles, K. Examination of Alternative Fabric Joining Techniques Compared to Traditional Sewing McNair Scholars Research Journal 5 (1) 2012: pp. 1-17.

10. Pethrick, R.A. Design and Ageing of Adhesives for Structural Adhesive Bonding - A Review Proceedings of the Institution of Mechanical Engineers, Part L: Journal of Materials: Design and Applications 229 (5) 2015: pp. 349-379. https://doi.org/10.1177/1464420714522981

11. Mikalauskaitė, G., Vadeikè, G., Daukantienè, V. Investigation of the Behaviour of Fibrous Materials' Adhesive Bonds CYSENI 2018: 15th International Conference of Young Scientists on Energy Issues 2018: pp. $392-398$.

12. Jones, I., Stylios, G. K. Joining Textiles: Principles and Applications. Woodhead Publishing, Cambridge, 2013: pp. 223-347.

13. Landrock, A.H., Ebnesajjad, S. Adhesives Technology Handbook. William Andrew, London, 2018: pp. 1-17.

14. Jakubčionienè, Ž., Masteikaitè, V., Kleveckas, T. Investigation of the Strength of Textile Bonded Seams Materials Science (Medžiagotyra) 18 (2) 2012: pp. $172-176$. http://dx.doi.org/10.5755/j01.ms.18.2.1922

15. Mikalauskaitè, G., Daukantienè, V. Influence of the Delamination Loading Velocity on Textile Bonds and Sewn Seams Strength International Journal of Clothing Science and Technology 29 (6) 2017: pp. 768-775. https://doi.org/10.1108/IJCST-02-2017-0012

16. Mikalauskaitè, G. Investigation and Evaluation of Textile Bonded Seams Delamination Strength, M.Sc. Thesis. Lithuania, Kaunas University of Technology. 2016.

17. Zmitrulevičius, E. Influence of the Bonding Temperature and Printing on the Strength of Knitted Fabric's Adhesive Bonds. M.Sc. Thesis. Lithuania, Kaunas University of Technology. 2018.

18. Hunter, L.W., White, J.W., Cohen, P.H., Biermann, P.J. A Materials Aging Problem in Theory and Practice Johns Hopkins APL Technical Digest 21 (4) 2000: pp. 575-581.

19. LST EN 15062. Adhesives for Leather and Footwear Materials: Solvent-based and Dispersion Adhesives. Testing Ageing of Bonds under Specified Conditions. 2006.

20. Boubakri, A., Haddar, N., Elleuch, K., Bienvenu, Y. Influence of Thermal Aging on Tensile and Creep Behavior of Thermoplastic Polyurethane Comptes Rendus Mécanique $339(10) \quad 2011$ p p. 666-673. https://doi.org/10.1016/j.crme.2011.07.003

21. Boubakri, A., Haddar, N., Elleuch, K., Bienvenu, Y. Impact of Aging Conditions on Mechanical Properties of Thermoplastic Polyurethane Materials \& Design 31 (9) 2010: pp. $4194-4201$. https://doi.org/10.1016/j.matdes.2010.04.023

22. LST EN ISO 5084. Textiles: Determination of Thickness of Textiles and Textile Products, 2000.

23. LST EN 12127. Textiles: Fabrics. Determination of Mass per Unit Area Using Small Samples. 1999.

24. LST EN 1049-2. Textiles: Woven Fabrics. Construction. Methods of Analysis. Part 2: Determination of Number of Threads per Unit Length. 1998. 
25. LST EN 14971. Textiles: Knitted Fabrics. Determination of Number of Stitches per Unit Length and Unit Area. 2006.

26. Mikalauskaitè, G., Daukantienė, V. Influence of Technological Parameters on the Adhesion Strength of Adhesive Bonded Textile Seams Book of Abstracts 16th World Textile Conference "AUTEX" 2016: pp. 218-220.

27. Mikalauskaitė, G., Daukantienė, V. Influence of Adhesive Polyurethane Film Type on Bond Strength Proceedings of the International Conference „Chemistry and Chemical Technology 48 2017: pp. 48.

28. LST EN ISO 139. Textiles: Standard Atmospheres for Conditioning and Testing. 2006.

29. Oliver, J.E. (Ed.). Encyclopedia of World Climatology. Springer, Dordrecht, Netherlands, 2008: pp. 219-272.

30. Adams, R.D. Adhesive Bonding: Science, Technology and Applications. Woodhead Publishing Limited, Cambridge, England, 2005: pp. $91-122$. 